\title{
Rancang Bangun Game Dreamcatcher : War Of Surabaya Dengan Permodelan Scrum
}

\author{
Boby Ferdianza ${ }^{1}$, Rani Rotul Muhima ${ }^{2}$, Hendro Nugroho ${ }^{3}$ \\ ${ }^{1,2,3}$ Teknik Informatika, Fakultas Teknologi Informasi, Institut Teknologi Adhi Tama Surabaya \\ Email : ${ }^{1}$ bobyferdianzai@gmail.com
}

\begin{abstract}
History belongs to a compulsory element in the teaching and learning at school. It can help students to know and more appreciate the past events. The number of history materials taught at school sometimes causes difficulty for students to learn. The lack of facilities and learning media which can attract student's interest becomes the main factors of student's difficulty in learning Social Science. Learning medium is very vital to determine what materials students can learn. One of solutions to solve difficulty in learning history is by creating new learning medium in the form of educational game as it can arouse student's ability in thinking. One of the games teaching history particularly the history of Surabaya is Dreamcatcher: War of Surabaya. This game was designed based on historical events in Surabaya composed in an attractive story. It is completed with quiz to improve student's memory. Game "Dreamcatcher: War of Surabaya" can be played with android platform and it is considered successful in teaching the history of Surabaya as it could improve students' abilities on Surabaya history by $113.7 \%$ based on the results of pre-and post-tests.
\end{abstract}

Keywords: History, Educational game

Abstrak. Sejarah merupakan unsur wajib dalam pembelajaran di sekolah. Sejarah dapat membantu para siswa mengetahui dan lebih menghargai tentang kejadian yang terjadi pada masa lampau. Semakin banyaknya materi sejarah yang diajarkan pada sekolah, terkadang siswa merasa kesulitan dalam mempelajari sejarah yang ada. Faktor yang menyebabkan siswa sulit dalam menerima pelajaran Ilmu Pengetahuan Sosial disebabkan kurangnya sarana dan media pembelajaran yang dapat menarik perhatian para siswa. Media yang digunakan dalam pembelajaran sangat menentukan apa yang didapat oleh siswa. Salah satu solusi untuk masalah tersebut adalah menciptakan sarana pembelajaran sejarah baru dengan game edukasi, dikarenakan game edukasi bisa merangsang daya pikir siswa. Salah satu game yang mengajarkan sejarah khususnya sejarah pada kota Surabaya adalah game Dreamcatcher : war of Surabaya. Game dirancang berlatar belakang sejumlah kejadian bersejarah di Surabaya yang disusun menjadi cerita yang menarik, Serta terdapat sebuah quiz pada game untuk membantu meningkatkan daya ingat terhadap siswa. Game Dreamcatcher : war of Surabaya dapat dimainkan pada platform android. Game Dreamcatcher : war of Surabaya dinilai cukup berhasil dalam mengajarkan sejarah kota Surabaya karena siswa mendapatkan peningkatan 113,7\% tentang kejadian bersejarah di Surabaya yang diambil dari hasil pretest dan posttest.

Kata Kunci: Sejarah, game edukasi 


\section{Pendahulan}

Sejarah adalah salah satu unsur wajib yang terdapat pada pelajaran ilmu pengetahuan sosial (IPS) di sekolah dasar (SD). Menurut kamus besar bahasa Indonesia, sejarah adalah kejadian atau peristiwa yang benar-benar terjadi pada masa lampau. Menurut Priyoga (2014) terkadang siswa merasa kesulitan dalam mempelajari serta memahami sejarah yang ada. Faktor yang menyebabkan siswa sulit dalam menerima pelajaran Ilmu Pengetahuan Sosial disebabkan kurangnya sarana dan media pembelajaran yang dapat menarik perhatian dan minat belajar siswa). Berdasarkan penelitian tersebut, perlu dilakukan pengembangan terhadap media pembelajaran yang dapat membantu siswa dalam memahami Ilmu pengetahuan sosial terutama sejarah.

Menurut Hendriyantini (2009) game edukasi adalah suatu permainan yang dirancang dan dibuat untuk merangsang daya pikir termasuk meningkatkan konsentrasi serta memecahkan masalah. Game edukasi ialah salah satu media yang digunakan untuk memberikan pengajaran serta menambah pengetahuan penggunanya melalui suatu media unik dan menarik. Jenis ini biasanya ditujukan untuk anak-anak.

Dalam pengimplementasian game edukasi untuk pembelajaran sejarah yang berjudul dreamcatcher : war of Surabaya, diperlukan adanya proses permodelan rekaya perangkat lunak, salah satunya menggunakan permodelan scrum. Sebagaimana penelitian yang dilakukan oleh Putu Adi Guna Permana (2015) tentang penggunaan permodelan scrum untuk development project perangkat lunak, scrum dapat menyesuaikan perubahan secara fleksibel karena scrum memiliki sistem looping atau perulangan pada proses permodelannya dan juga scrum dapat mendokumentasikan secara lengkap tentang apa yang telah dikerjakan. scrum juga cocok dengan project yang dikerjakan oleh perseorangan atau tim berukuran kecil karena proses pada scrum mampu menyatakan bahwa produk dapat selesai kapanpun.

\section{Tinjauan Pustaka}

\subsection{Game edukasi}

Game atau permainan edukasi yaitu permainan secara perorangan atau kelompok yang berhubungan dengan edukasi atau tujuan pendidikan. Permainan edukasi memiliki cukup banyak bentuk, permainan kartu, seperti permainan papan, maupun permainan dalam video game (Insanittaqwa, 2014). Pada game edukasi ada paduan antara narasi serta animasi yang membuat pemain tertarik, sehingga permainan mempunyai potensi besar dalam membangun motivasi pemain. Game membuat pemain merasa senang serta nyaman dalam mengikuti pembelajaran. Bukan hanya menghindarkan dari kebosanan, kegiatan pembelajaran yang heboh menggunakan media game akan meninggalkan kesan yang cukup lama dalam memori pemain, serta juga memberikan peluang kepada pemain untuk belajar dengan suasana yang lebih menyenangkan tanpa meninggalkan tujuan pembelajaran (Sari, 2014).

\subsection{Permodelan Pada Perangkat Lunak}

Permodelan perangkat lunak merupakan suatu strategi tentang pengembangan yang memadukan metode serta lapisan proses dan tahap-tahap generik. Model proses untuk rekayasa perangkat lunak dipilih berdasarkan metode dan alat yang digunakan, sifat proyek dan aplikasi, serta pengendalian dan hasil yang diinginkan (Nugroho, 2009).

\section{Perancangan Sistem}

\subsection{Kompetensi dan Tantangan Penidikan}

Kompetensi dan tantangan pendidikan berguna sebagai dasar dari unsur edukasi pada game "Dreamcathcer : War of Surabaya". Pengumpulan data dilakukan dengan teknik wawancara kepada pemangku kepentingan. Unsur edukasi sejarah yang dibahas dalam game, diambil beberapa yang sesuai dengan ruang lingkup game "Dreamcathcer : War of Surabaya" dari silabus mata pelajaran IPS kelas 5 \& 6 kurikulum 2013. Setelah mendapatkan pokok 
bahasan, tahap selanjutnya adalah proses pengumpulan data kronologis kejadian bersejarah pada kota Surabaya. Data yang diambil adalah data dari literatur pada museum Tugu Pahlawan Surabaya dengan teknik wawancara terhadap pihak pemandu wisata pada museum Tugu Pahlawan Surabaya.

\subsection{Karakteristik Game}

Tahap selanjutnya adalah menentukan karakteristik pada game. Perancangan karakteristik sangatlah diperlukan . Dikarenakan perancangan karakteristik akan menjadi dasar dalam pembuatan game "Dreamcathcer : War of Surabaya" dalam memilih platform, target pengguna, ruang lingkup game dan jenis game seperti pada Tabel 1.

Tabel 1 Karakteristik pada game "Dreamcathcer : War of Surabaya"

\begin{tabular}{cll}
\hline No. & \multicolumn{1}{c}{ Analisa kebutuham } & \multicolumn{1}{c}{ Keterangan } \\
\hline 1. & Jenis kelamin pengguna & $\begin{array}{l}\text { 1. Laki-laki. } \\
\text { 2. Perempuan }\end{array}$ \\
\hline 2. & Platform Permainan & Hand Phone yang berbasis Android \\
\hline 3. & $\begin{array}{l}\text { Kontrol Karakter } \\
\text { Permainan }\end{array}$ & Dengan menekan tombol yang berada pada layar game \\
\hline 4. & Ruang Lingkup Game & Kejadian bersejarah pada kota Surabaya \\
\hline 5. & Target Pengguna & Siswa dan siswi SD Sasana Bakti Surabaya \\
\hline 6. & Jenis game & $R P G$ (role playing game $)$ \\
\hline
\end{tabular}

\subsection{Permodelan scrum}

a. Product Backlog

Pada proses product backlog, segala kebutuhan user atau pengguna dicatat \& diurutkan berdasarkan prioritas. Pada setiap proses diberikan batas waktu pengerjaan. Untuk game "Dreamcathcer: War of Surabaya" terdapat 3 prioritas utama dalam pengerjaan, seperti pada tabel 2.

Tabel 2 Product Backlog

\begin{tabular}{ccc}
\hline Bulan & Desription & Estimasi \\
\hline 1 & Game design & 31 hari \\
\hline 2 & Game programming & 21 hari \\
\hline 3 & Sound composer & 15 hari \\
\hline
\end{tabular}

\section{b. Sprint Planning \& Sprint Backlog}

Tahap Sprint Planning bertujuan untuk merencanakan pekerjaan apa sajakah yang akan dilakukan oleh pengembang selama satu Sprint. Dalam game "Dreamcathcer : War of Surabaya" sprint planning atau rincian setiap pekerjaan yang terdapat pada product backlog telah dibuat dengan 3 sprint.

Tabel 3. Sprint backlog tahap 1

\begin{tabular}{|c|c|c|c|c|c|c|c|}
\hline & \multirow[b]{2}{*}{ Deskripsi } & \multicolumn{6}{|c|}{ Bulan 1} \\
\hline & & $\begin{array}{c}\text { Minggu } \\
1\end{array}$ & $\begin{array}{c}\text { Minggu } \\
2\end{array}$ & $\begin{array}{c}\text { Minggu } \\
3\end{array}$ & $\begin{array}{c}\text { Minggu } \\
4\end{array}$ & $\begin{array}{c}\text { Minggu } \\
5\end{array}$ & $\begin{array}{c}\text { Minggu } \\
6\end{array}$ \\
\hline \multirow{3}{*}{$\begin{array}{l}\text { Game } \\
\text { design }\end{array}$} & Desain mini story & 3 hari & 3 hari & & & & \\
\hline & $\begin{array}{c}\text { Desain level } \\
\text { game }\end{array}$ & & & 4 hari & & & \\
\hline & $\begin{array}{c}\text { Desain karakter \& } \\
\text { NPC }\end{array}$ & & & & 3 hari & 4 hari & 4 hari \\
\hline
\end{tabular}




\begin{tabular}{ccccc}
\hline $\begin{array}{c}\text { Desain menu } \\
\text { game }\end{array}$ & \multicolumn{2}{c}{2 hari } & 2 hari \\
\cline { 2 - 5 } $\begin{array}{c}\text { Desain quiz pada } \\
\text { game }\end{array}$ & 2 hari & 2 hari & 2 hari & \\
\hline
\end{tabular}

\section{c. Sprint Excecution}

sprint excecution adalah tahap untuk mengerjakan pekerjaan yang sudah ditetapkan pada sprint backlog untuk game "Dreamcatcher : War of Surabaya". Pada penelitian ini proses daily scrum meeting tidak digunakan, karena proses pembuatan game hanya dilakukan secara individu, sedangkan daily scrum meeting harus diadakan setiap hari oleh semua tim untuk mencocokan apa yang telah dikerjakan. Contoh dari sprint excecution yang telah dilakukan bisa dilihat dari gambar 1 dan 2.
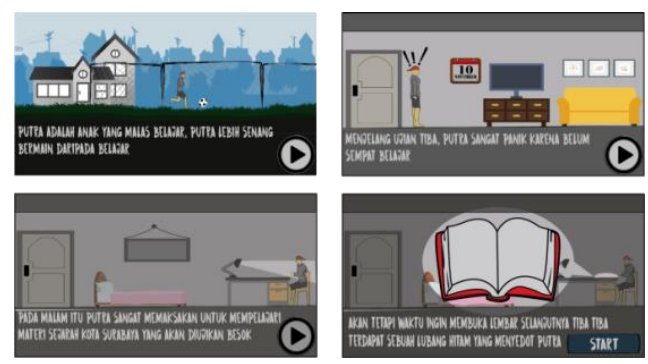

Gambar 1.Tampilan mini story latar belakang cerita
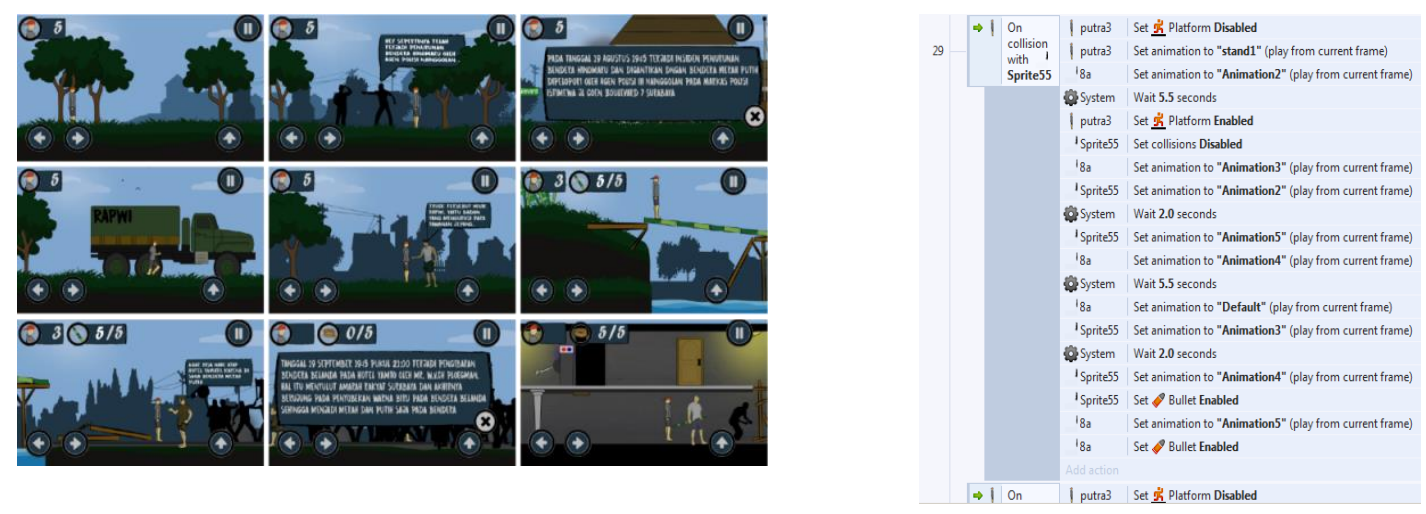

Gambar 2. Tampilan level 1 dan event level 1

\section{d. Shippable Product Increment}

Tahap Shippable Product Increment adalah tahap pengujian game "Dreamcatcher : War of Surabaya" oleh pembuat game dengan menggunakan metode black box testing sebelum diujikan ke stakeholder atau pemangku kepentingan secara langsung. Pengujian dilakukan dengan cara menguji setiap fitur yang terdapat pada game, apakah sudah valid atau masih terdapat bug seperti pada tabel 4. 
Tabel 4 Pengujian black box testing

\begin{tabular}{|c|c|c|c|}
\hline No & Skenario pengujian & Hasil yang diharapkan & Keterangan \\
\hline \multirow[t]{2}{*}{1} & $\begin{array}{l}\text { Klik button menu info pada } \\
\text { halaman utama }\end{array}$ & Menu info akan tampil & \multirow[b]{2}{*}{ Valid } \\
\hline & 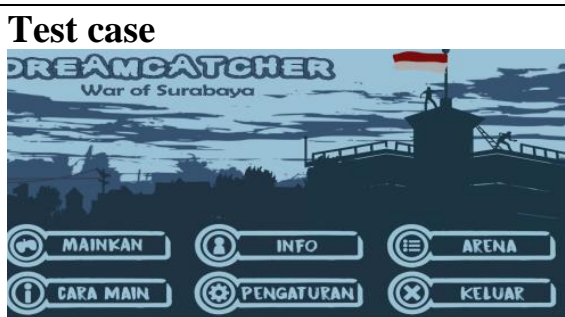 & 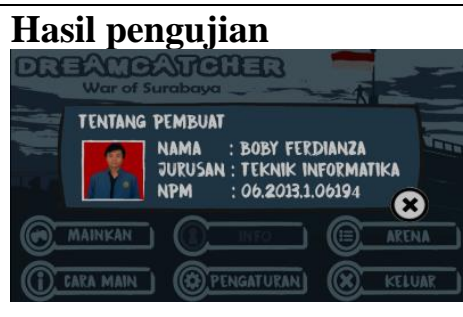 & \\
\hline \multirow[t]{3}{*}{2} & $\begin{array}{l}\text { Klik button menu cara main pada } \\
\text { halaman utama }\end{array}$ & Menu cara main akan tampil & \multirow{3}{*}{ Valid } \\
\hline & 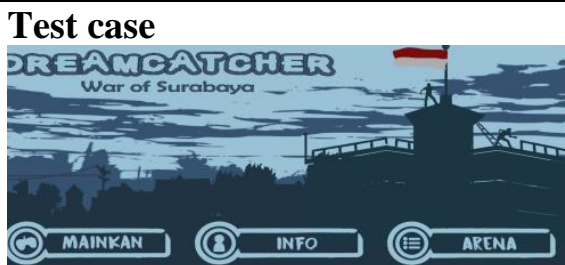 & 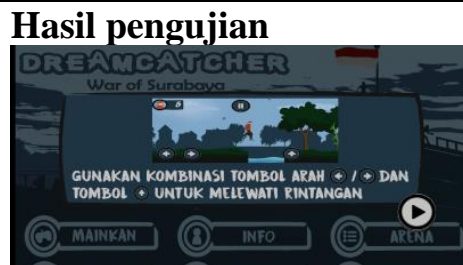 & \\
\hline & (1) GARA MAIN (i) PENGATURAN (2) KELUAR & 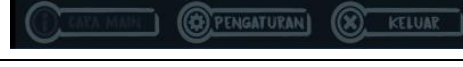 & \\
\hline
\end{tabular}

\section{e. Sprint Review}

Sprint review adalah proses game "Dreamcatcher : War of Surabaya" direview dan dievaluasi oleh pemangku kepentingan maupun tester. proses evaluasi atau pengujian pada game "Dreamcatcher : War of Surabaya" terdapat 2 bagian, antara lain:

\section{Hasil kuisioner yang dilakukan kepada stakeholder}

Evaluasi pada game "Dreamcatcher : War of Surabaya" dilakukan dengan memberikan kuisioner kepada pemangku kepentingan pada SD Sasana Bhakti Surabaya. Hasil dari kuisioner disajikan menggunakan metode skala likert sesuai pada tabel 5.

Tabel 5. Hasil dari skala likert kuisioner pada pemangku kepentingan SD Sasana Bhakti Surabaya

\begin{tabular}{|c|c|c|c|c|c|c|c|c|c|c|c|c|c|c|}
\hline \multirow[b]{2}{*}{ No } & \multirow[b]{2}{*}{ Pernyataan } & \multicolumn{5}{|c|}{ Jawaban user } & \multicolumn{5}{|c|}{ Skala likert } & \multirow{2}{*}{$\begin{array}{l}\text { Total } \\
\text { score }\end{array}$} & \multirow{2}{*}{$\begin{array}{l}\text { present } \\
\text { ase }\end{array}$} & \multirow{2}{*}{$\begin{array}{c}\text { interpr } \\
\text { etasi }\end{array}$} \\
\hline & & st & ts & $\mathbf{c}$ & $\mathbf{s}$ & SS & st & ts & $\mathbf{c}$ & $\mathbf{s}$ & SS & & & \\
\hline \multicolumn{15}{|c|}{ Usability } \\
\hline 1 & $\begin{array}{l}\text { Permainan dalam game } \\
\text { ini mudah untuk digunakan }\end{array}$ & 0 & 0 & 2 & 1 & 0 & 0 & 0 & 6 & 4 & 0 & 10 & $66,66 \%$ & Baik \\
\hline 2 & $\begin{array}{l}\text { Permainan dalam game } \\
\text { dapat dipakai latihan siswa }\end{array}$ & 0 & 0 & 0 & 0 & 3 & 0 & 0 & 0 & 0 & 15 & 15 & $100 \%$ & $\begin{array}{l}\text { Sangat } \\
\text { setuju }\end{array}$ \\
\hline 3 & $\begin{array}{l}\text { Permainan dapat membantu } \\
\text { siswa dalam belajar sejarah }\end{array}$ & 0 & 0 & 0 & 1 & 2 & 0 & 0 & 0 & 4 & 10 & 14 & $93,33 \%$ & $\begin{array}{l}\text { Sangat } \\
\text { setuju }\end{array}$ \\
\hline Rat & rata presentase & $6+$ & $00+$ & 93,3 & - & 599 & .3 & 86, & & & & & $6 \%$ & gat setuju \\
\hline \multicolumn{15}{|c|}{ Information Quality } \\
\hline 4 & $\begin{array}{l}\text { Soal - soal dalam permainan } \\
\text { ini sesuai dengan yang } \\
\text { diajarkan di kelas }\end{array}$ & 0 & 0 & 2 & 1 & 0 & 0 & 0 & 6 & 4 & 0 & 10 & $66,66 \%$ & Setuju \\
\hline 5 & Soal dalam permainan sesuai & 0 & 0 & 0 & 2 & 1 & 0 & 0 & 0 & 8 & 5 & 13 & $86,66 \%$ & Sangat \\
\hline
\end{tabular}


dengan kompetensi yang

setuju

harus di capai oleh siswa

\begin{tabular}{lllllllllllllll}
\hline $\mathbf{6}$ & $\begin{array}{l}\text { Tulisan dalam game ini dapat } \\
\text { dibaca dengan jelas }\end{array}$ & 1 & 2 & 0 & 0 & 0 & 1 & 4 & 0 & 0 & 0 & 5 & $33,3 \%$ & $\begin{array}{l}\text { Tidak } \\
\text { setuju }\end{array}$ \\
\hline $\mathbf{7}$ & $\begin{array}{l}\text { Audio dalam game ini dapat } \\
\text { didengar dengan jelas }\end{array}$ & 0 & 0 & 1 & 1 & 1 & 0 & 0 & 3 & 4 & 5 & 12 & $80 \%$ & $\begin{array}{l}\text { Sangat } \\
\text { setuju }\end{array}$ \\
\hline $\mathbf{8}$ & $\begin{array}{l}\text { Petunjuk Dalam permainan } \\
\text { jelas }\end{array}$ & 0 & 0 & 0 & 2 & 1 & 0 & 0 & 0 & 8 & 5 & 13 & $86,66 \%$ & $\begin{array}{l}\text { Sangat } \\
\text { setuju }\end{array}$ \\
\hline Rata rata presentase & $86,66+33,3+80+86,66=286,62: 4=70,65$ & & $70,65 \%$ & Setuju
\end{tabular}

\begin{tabular}{lllllllllllllll}
\hline Interaction Quality & & & & & & & & $\begin{array}{l}\text { Sangat } \\
\text { setuju }\end{array}$ \\
\hline $\mathbf{9}$ & $\begin{array}{l}\text { Menu dalam permainan ini } \\
\text { sudah sesuai fungsinya }\end{array}$ & 0 & 0 & 1 & 1 & 1 & 0 & 0 & 3 & 4 & 5 & 12 & $80 \%$ & $\begin{array}{l}\text { Sangat } \\
\text { setuju }\end{array}$ \\
\hline $\mathbf{1 0}$ & $\begin{array}{l}\text { Menu dalam permainan ini } \\
\text { sesuai kebutuhan }\end{array}$ & 0 & 0 & 0 & 1 & 2 & 0 & 0 & 0 & 4 & 10 & 14 & $93,33 \%$ \\
\hline $\mathbf{1 1}$ & $\begin{array}{l}\text { Tombol permainan mudah } \\
\text { digunakan }\end{array}$ & 0 & 0 & 0 & 2 & 1 & 0 & 0 & 0 & 8 & 5 & 13 & $86,66 \%$ & $\begin{array}{l}\text { Sangat } \\
\text { setuju }\end{array}$ \\
\hline $\mathbf{1 2}$ & Ukuran tombol sesuai & 0 & 0 & 1 & 2 & 0 & 0 & 0 & 3 & 8 & 0 & 11 & $73,33 \%$ & setuju \\
\hline $\mathbf{1 3}$ & $\begin{array}{l}\text { Waktu yang diberikan dalam } \\
\text { menjawab soal sudah sesuai }\end{array}$ & 0 & 1 & 2 & 0 & 0 & 0 & 2 & 6 & 0 & 0 & 8 & $53,33 \%$ & Cukup \\
\hline Rata rata presentase $80+93,33+86,66+73,33+53,33=386,65$ & & & $77,33 \%$ & Setuju \\
\hline
\end{tabular}

\section{Pengujian keberhasilan pengajaran sejarah}

Pengujian keberhasilan pengajaran sejarah game "Dreamcathcer : War of Surabaya" pada SD Sasana Bakti Surabaya dilakukan ketika game sudah jadi dan dapat digunakan. Pengujian dilakukan dalam 2 tahap, yaitu pre test dan post test. Pre test dilakukan sebelum siswa melakukan percobaan pada game, dengan cara memberikan sejumlah soal yang berkaitan dengan unsur edukasi game. Post test dilakukan setelah siswa melakukan percobaan pada game, dengan cara memberikan soal yang sama seperti pre test. Pada pengujian pre test dan post test terdapat 14 soal yang di isi oleh para siswa. Setelah mendapatkan hasil pengujian pada siswa dilakukan perhitungan untuk menentukan peningkatan yang dialami setiap siswa dengan cara :

Hasil pengurangan $=$ Post test - pre test

Hasil pembagian $=$ Hasil pengurangan $:$ pre test

Presentase $=$ hasil pembagian $\mathrm{x} 100$

Tabel 6 Hasil pre test dan post test

\begin{tabular}{|c|c|c|c|c|c|c|}
\hline \multirow[b]{2}{*}{ NO } & \multirow[b]{2}{*}{ NAMA } & \multicolumn{2}{|c|}{ JAWABAN BENAR } & \multirow{2}{*}{$\begin{array}{c}\text { HASIL } \\
\text { PENGURANGAN }\end{array}$} & \multirow[b]{2}{*}{$\begin{array}{l}\text { PRESENTASE } \\
\text { KENAIKAN }\end{array}$} & \multirow[b]{2}{*}{ KETERANGAN } \\
\hline & & $\begin{array}{l}\text { PRE } \\
\text { TEST }\end{array}$ & $\begin{array}{l}\text { PAST } \\
\text { TEST }\end{array}$ & & & \\
\hline 1 & $\begin{array}{l}\text { Jonathan } \\
\text { Novandi }\end{array}$ & 7 & 5 & -2 & $-28 \%$ & Penurunan \\
\hline 2 & J Venny W & 5 & 8 & 3 & $60 \%$ & Kenaikan \\
\hline 3 & Kristina & 2 & 7 & 5 & $250 \%$ & Kenaikan \\
\hline 4 & Jonathan A & 2 & 6 & 4 & $200 \%$ & Kenaikan \\
\hline 5 & Dania & 3 & 6 & 3 & $100 \%$ & Kenaikan \\
\hline 6 & Patricia & 3 & 4 & 1 & $33.33 \%$ & Kenaikan \\
\hline 7 & Elizabeth & 2 & 4 & 2 & $100 \%$ & Kenaikan \\
\hline 8 & Brohmo & 5 & 4 & -1 & $-20 \%$ & Penurunan \\
\hline 9 & Putra C K & 4 & 8 & 4 & $100 \%$ & Kenaikan \\
\hline 10 & Nathania & 4 & 7 & 3 & $75 \%$ & Kenaikan \\
\hline
\end{tabular}




\begin{tabular}{l}
$\begin{array}{l}\text { Siswa yang berhasil mengalami peningkatan : } \\
8 \text { orang }\end{array}$ \\
$\begin{array}{l}\text { Siswa yang belum berhasil mengalami peningkatan : } 2 \\
\text { orang }\end{array}$ \\
\hline $\begin{array}{l}\text { Rata rata kenaikan pada siswa SD Sasana Bhakti kelas } 6 \text { adalah : } \\
(-28)+60+250+200+100+300+100+(-20)+100+75=1233: 10=113,7 \%\end{array}$ \\
\hline
\end{tabular}

\section{f. Sprint Retrospective}

Sprint retrospective adalah tahap pengembang atau pembuat game "Dreamcatcher : War of Surabaya" meninjau tentang sprint review yang telah dilakukan, serta mengidentifikasi dan mengurutkan hal-hal utama yang berjalan baik dan hal-hal yang berpotensi untuk ditingkatkan pada game "Dreamcatcher : war of Surabaya". Hasil dari sprint retrospective game "Dreamcatcher : War of Surabaya" seperti pada gambar 3 akan ditinjau ulang oleh pemangku kepentingan SD Sasana Bhakti Surabaya.
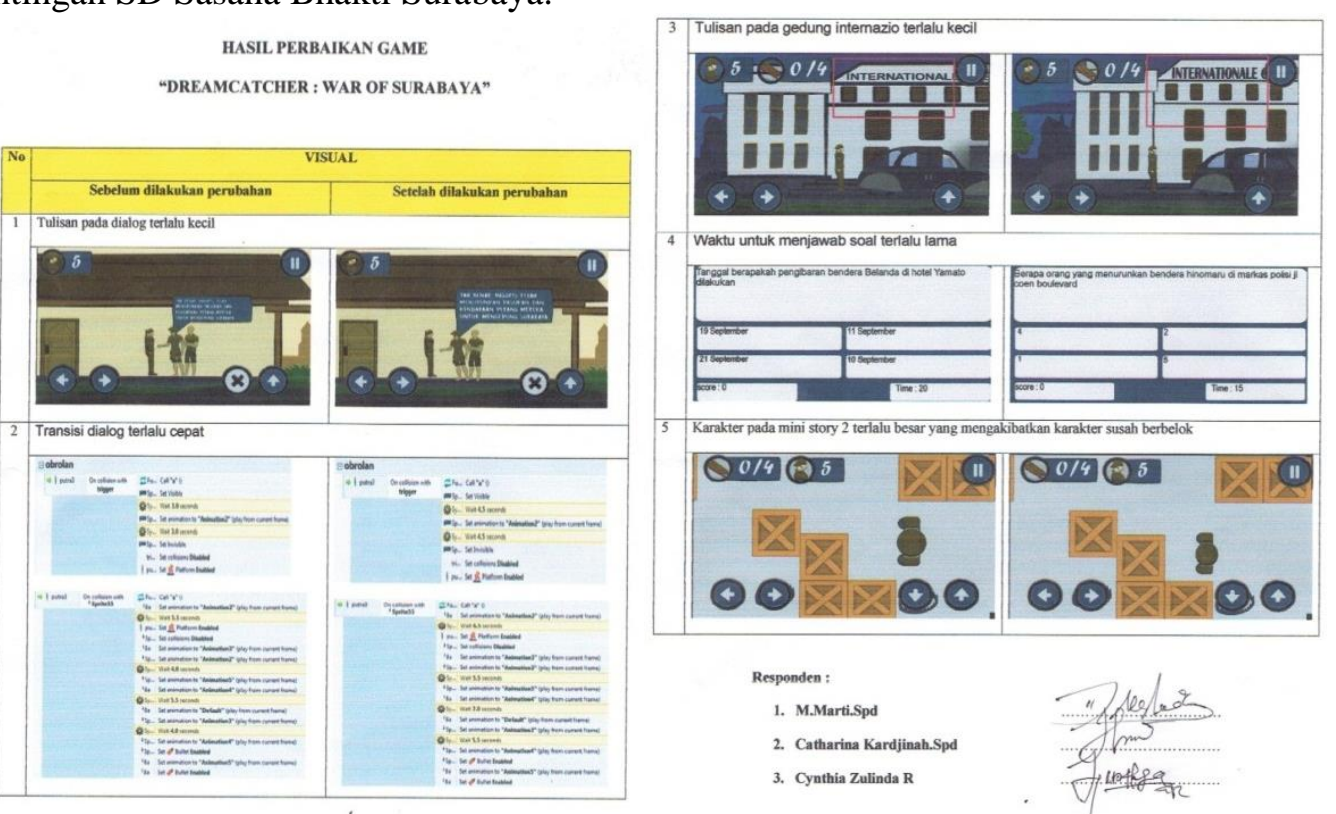

\section{Kesimpulan}

Gambar 3. Tampilan Sprint retrospective

Kesimpulan penelitian rancang bangun game "Dreamcatcher : war of Surabaya" dengan permodelan scrum adalah :

1. Telah berhasil dibuat game edukasi tentang pembelajaran sejarah kota Surabaya, berjudul "Dreamcatcher: War of Surabaya". Pembuatan game dilakukan dengan menggunakan permodelan scrum.

2. Pengimplemenasian permodelan scrum pada game "Dreamcatcher : War of Surabaya" melalui tahapan sprint planning, sprint backlog, sprint excecution, Shippable Product Increment, sprint review dan sprint retrospective berasil dilakukan. Hal ini ditunjukkan dari Usability yang menunjukkan kemudahan dalam menggunakan game "Dreamcatcher: War of Surabaya" sebesar $86,66 \%$, Information quality yang menunjukkan kualitas informasi yang diberikan sebesar $70,65 \%$ serta Interaction quality yang menunjukkan kualitas interaksi terhadap user sebesar 77,3\%.

Pengajaran sejarah pada SD Sasana Bhakti melalui media game dinyatakan berhasil karena siswa memiliki rata-rata kenaikan tentang pengetahuan sejarah kota Surabaya sebesar 11

\section{Referensi}

Handriyantini, Eva. 2009. Permainan Edukatif (Educational Games) Berbasis Komputer untuk Siswa Sekolah Dasar. Skripsi. Malang: Sekolah Tinggi Informasi \& Komputer Indonesia. 
Insanittaqwa Vika Fitratunnanya, Imam Kuswardayan. 2014. Game edukasi simulasi haji menggunakan ren py pada perangkat android . Skripsi. Surabaya: Institut Teknologi Sepuluh November.

Nugroho Eddy Prasetyo, Komala Ratnasari. 2009. Rekayasa Perangkat Lunak. Skripsi. Bandung: Telkom Polytechnic Bandung.

Permana Putu Adi Guna. 2015. Scrum Method Implementation In A Software Development Project Management. Skripsi. Denpasar: STMIK STIKOM Bali.

Priyoga Singgih Catur. 2014. Analisis kesulitan belajar siswa dalam pembelajaran ilmu pengetahuan sosial di kelas v. Skripsi. Pontianak: Universitas Tanjungpura.

Sari Kurnia Wening. 2014. Pengembangan game edukasi kimia berbasis role playing game pada materi struktur atom. Skripsi. Surakarta: Universitas Sebelas Maret. 